\title{
Teachers Problems and Countermeasures of Bilingual Education for Xi'an Preschool
}

\author{
Xiaoqian KANG \\ Xi'an University \\ Xi'an 710065, China
}

\begin{abstract}
This paper presents problems of lacking pre-school bilingual English education capacity in Preschool Education, and solves this problem, combined with pre-school bilingual education teachers should have the English ability, and the author elaborates that in Preschool Bilingual Education New Teacher of English Education training capacity we should highlight the importance of English language skills, pre-school children English teaching skills and practical skills such as teaching.
\end{abstract}

Keywords- pre-school bilingual education; English; educational capacity; training

\section{INTRODUCTION}

With the pre-school bilingual education carried out in full swing, the issue of education has also been revealed. Chief among them is the shortage of teachers and that teachers' English ability lacks education issues. Professor Zhou Jing pointed out that our pre-school bilingual education has problems at a practical level, there are some basic questions: many teachers due to lack of original English language proficiency can not naturally contact and interact in English with children, practice and repetition behind the mechanical hide serious English input scarcity; there are problems that young children in English class lack standard English, "Chingelish" is abound in young children learning. [1] We are in the process of lectures kindergarten, pre-school bilingual teacher is found there, such as spoken English is weak, the tone of voice is not standard, they can not properly use English everyday in kindergarten to teach. School teacher is the key to the success of bilingual education; it is an imitation of role models and the main input source infant language acquisition, therefore, the availability of qualified English teachers is one of the decisive factors that can carry out a bilingual kindergarten education. Strengthen the training of bilingual teachers in pre-school; in particular the ability to train English education has become an important prerequisite for the healthy development of bilingual preschool education.

\section{ABILITY OF BILINGUAL TEACHERS TO TEACH ENGLISH}

Bilingual education pre-school teachers are kindergarten teachers who are qualified and English teachers set as one of the "Double Teachers". According to the characteristics of bilingual education for pre-school, we highlighted the "listening and speaking (with singing)" requirements, followed by "master a foreign language and literacy teaching theory" aspect, while the other side is relatively lower requirements. Therefore, as for pre-school bilingual education teacher of English ability, I believe English should be able to use the knowledge, listening, speaking and language skills (including singing), and they are used in line with the characteristics of pre-school teaching methods to organize English teaching activities, and English nursery can use everyday language to communicate with children, and use kindergarten ability to organize various activities.

Correctly grasping the "pre-school bilingual education" policy-oriented bilingual kindergarten education is still just an experiment, purpose of the experiment is to study on the basis of mother tongue, which is the basis of standard Mandarin learning on elementary education a second language to stimulate children's interest in learning a second language, know foreign cultures, and create conditions for their future learning to lay the foundation. This is a policyoriented issue. Although our country learning English education policy from the beginning is in the third grade and "pre-school bilingual education" is currently in the country becoming hot and has much public attention, which requires us to pre-school bilingual education for serious thinking, and right boot. In particular, because "bilingual education" requirements preschool teachers in the province are far away from the conditions, in the course of the experiment, we should cultivate a group of "qualified bilingual teachers' teachers, and providing training opportunities for them is as a priority, bilingual teaching materials and environmental optimization of conditions can not be ignored.

\section{III. "PRESCHOOL BILINGUAL EDUCATION" TARGETING}

The purpose is to learn English so that children learn on the basis of mother tongue, a second language (referring to English) elementary education cultivates their interest in a second language, they learn to absorb foreign cultures, and it creates conditions for their future learning, laying a good foundation. The depth of children learning English progress is not our ultimate goal, cultivating their 'bilingual' interest in learning is we intend to pursue, they can make a lifetime of learning for the future and lay the foundation for sustainable development. Therefore, targeting early childhood bilingual education should be: first, the goal of bilingual education 
preschool children to comply with the law of the harmonious development of body and mind, in line with the law and young children learn language, we should coincide with the goal of basic education; second, to foster children for "bilingual" learning enthusiasm and interest in and use of language habits, so that they feel the differences in cultural backgrounds in bilingual education; and third, to let children learn relaxed, and make them interested to learn, in this we should pay attention to teaching standards.

\section{TEACHING ABILITY OF BILINGUAL EDUCATION TEACHERS}

Preschool Bilingual education means educational activities in kindergarten, first acquisition in children is on the basis of mother tongue, according to the characteristics of children's physical and mental development and language learning law, through the creation of a suitable environment pre-school children develop interest and sensitivity as well as bilingual preliminary oral communication capacity to a second language (mainly English), and promote the comprehensive development of their teaching activities.

With the development and application of the Ministry of Education, "Eleventh Five-Year" key issues "new bilingual preschool teacher training" are conducted, people are aware of bilingual pre-school English teaching capacity requirements for new teachers. As a qualified bilingual preschool teachers, they should have the ability in English teaching in two aspects: First, the higher the comprehensive English language ability, including a more systematic and solid foundation in English and English language skills, such as the proper standard English pronunciation and intonation and strong English listening and speaking ability; the second is strong English teaching skills, including knowledge of the basic theory of pre-school children English teaching, they can use proper English teaching skills and methods before the children's ability to learn, such as listening, speaking, acting and other skills organizations infants The story of English teaching activities, games, activities and other kindergarten children English variety of English teaching activities.

"Pre-school English Integrated Course" pays full attention to the importance of classroom teaching practice, the fifth book in the textbook provides students with examples of early childhood system introduced English education activities and design programs that can help students master a good early childhood education program written in English, and the structure, format and methods for students to classroom teaching practice provides a good paradigm. When Professor "Preschool Comprehensive English" guide students to be familiar with the kindergarten English education activities designed structure, after the format, we use textbooks in English songs, English games, science and technology small production, etc., so that students in the simulation kindergarten, micro classrooms, and etc. scenarios to practice teaching exercise. Try to teach through video playback, group discussion and guide students through teaching methods, teaching design, teaching organization and so on. Students observe, perceive, demonstrate, simulate through intensive training and a series of activities to effectively improve teaching comprehensive practical ability.

\section{SPECIFICATIONS OF BILINGUAL TEACHERS' PROFESSIONAL STANDARD}

The inherent quality of early childhood education philosophy teacher professional awareness humanities are important factors to dominate its educational activities, and it is the fundamental factors affecting the effectiveness of their teaching, which determines the correct philosophy of education and teaching the scientific validity of the process of teaching proper behavior preschool bilingual education philosophy, including teachers of pre-school bilingual education, which has a positive right attitude, the principle of pre-school bilingual education meaning purpose is followed by a clear and reasonable understanding, etc. in particular, as before, a bilingual teacher should form below basic concept of bilingual education: a clear kindergarten bilingual education should be based on the development of the mother tongue of the child, the mother tongue and English proficiency teacher education organize games, activities and all aspects of daily life, and the children were in the process of enlightenment explicitly multicultural preschool, and the main purpose of bilingual education is not to let children learn how much, but rather to stimulate interest in learning the language of children, enhance the sensitivity of children to language for children to initially feel different ethnic and cultural diversity of this, it clearly can not be divorced from kindergarten bilingual education outside the kindergarten education system, but should permeate the teachers be as a medium of language and communication tool for organizing educational activities for young children to open a new window with a clear understanding of the world of bilingual education in kindergarten day life, it is to be with closely kindergarten education as a whole, on the basis of priority to the development of children's ability we use the native language to ensure coordination between Chinese and English bilingual children's development, pre-school bilingual education should be based on actual kindergarten education, kindergarten teachers are familiar with the current child receptive theme of education in the form of activities, naturally bilingual learning will be into educational activities in all areas of kindergarten, making it an integral part of kindergarten education.

To ensure the quality of bilingual education in kindergarten, kindergarten bilingual teacher training focus of the study should be located in a bilingual teacher in-service training. Teachers guide children to establish the scientific concept of pre-school bilingual education. Studies have shown that pre-verbal stage is the critical period of learning the mother tongue. People do not like learning a second language as first language learning has a particularly critical period of development, although the second language learning will bring people a role in promoting development. We should recognize the value of children's English 
language development and other aspects of development, but not blindly exaggerate the significance of learning English. Especially since China is not "balanced" bilingual education or bilingual learning environment for preschool children --Mandarin language learning should be no doubt in the first language of education. Any influence of development of children's mother tongue second language education programs for children are likely to lead to the development of serious mistakes. I believe that the English pre-school children's educational objectives should be: first, children develop an interest in learning English, improve the use of language to interact enthusiasm. Second, help children build a sense of initial English voice, increase their language sensitivity.

Guide children to choose the course of English textbooks and be able to use appropriate methods of teaching. We advocate early childhood teachers to choose curriculum reform which is consistent with the current thinking of teaching, and it is as far as possible integrated with Chinese courses; use high quality language teaching aids (mainly audio-visual materials); make efforts to create child care standards, natural English learning environment to improve the quantity and quality of language input; use appropriate teaching methods. It should be said, the teaching method itself is not good or bad, its main effect is a reasonable choice and flexibility in the use of the user. Teachers use more experimental garden methods are: (1) form from content, there are games, songs, stories, etc; (2) teaching methods with different learning modes, such as demonstrations, participation, exercise, expression and creation play roles. Emphasis on teaching methods should be evaluated using the scenario and natural acquisition, which is effective and useful holistic learning.

\section{CURRICULUM RESEARCH OF BILINGUAL EDUCATION TEACHER TRAINING SCHOOL}

The course is a pillar of achieving course objectives, preschool bilingual education teacher training courses should be made compulsory courses, elective courses and educational practice course consists of three parts, combine the three, we can play the whole function of education. Research is on how to select and set before school bilingual education teacher training courses to explore, including curriculum based on the principles of curriculum, course content and other classification.

Pre-school bilingual education research faculty building approach, the initial formation of the theoretical system of bilingual teacher training, bilingual teachers as the most direct perpetrators of bilingual teaching and bilingual teaching tasks to complete the most important person to reach its goal of bilingual teaching quality and it will play key role. Therefore, the issue of bilingual teachers has initial formation of a bilingual teacher training theoretical system on how to do a good job of bilingual teachers. Training
Principles establish a teacher-centered professional development; teacher training should help teachers to solve problems in the process of teaching, focus on a variety of ways and incentives to motivate their inherent passion for learning and motivation, active participate in the training process, and diversify bilingual teacher training methods.

\section{CONCLUSIONS}

Practice of Bilingual Education Preschool teacher training to help build a qualified bilingual preschool teacher norms and lead the healthy development of bilingual education, but pre-school bilingual education is a pre-school in specific areas, there are research studies related to a short time, experimental study of small research has remained mostly on experience, and quantitative data is less, the current bilingual teachers in terms of both quantity and quality can not meet the needs of pre-school bilingual education. Xi'an former bilingual education will train qualified teachers and play a successful implementation of this study guiding role, provides a strong guarantee for the development of pre-school bilingual education and empirical research for professional bilingual pre-school teacher training colleges in our country related in accordance with.

Acknowledgement

Fund Project: This paper is Xi'an Social Fund Project 13WL01 results.

\section{References}

[1] Chen Xuemei, Zhao Fang bilingual education preschool teacher specifications and professional development [J] pre-study, 2010,05: $39-43+49$.

[2] Zhang Jianbo, Yang Wenjuan the status quo of bilingual education teacher and school practice bases countermeasures [J] theory before observation, 2013,05: 144-145.

[3] Wei Qing Research and Exploration preschool bilingual education teacher training [J] intelligence, 2014,27: 77.

[4] Tan Xuan Problems and Solutions of preschool bilingual education teachers exist [J] Suzhou Education Institute, 2014,05: 79-80.

[5] Qian Feng Practice and Thinking of bilingual education for preschool teacher training $[\mathrm{J}]$ Jiangsu Education College (Social Sciences), 2007,03: 58-59.

[6] Huang Fang On Cultivation of New Preschool Bilingual Education Teachers' English ability [J] Sichuan College of Education, 2007,10: 41-43.

[7] Yang Lihua "Preschool Bilingual Education" [J] Kunming Teachers College, 2006,01: 66-68 + 72.

[8] Yang Lihua training before the new five-year study of bilingual education teachers to improve the quality and capabilities of [J] Kunming Teachers College, 2008,02: 95-98.

[9] Xuqiong Hua On the Implementation Preschool Bilingual Education [J] Sichuan College of Education, 2005,08: 9-10 + 12 . 